\title{
ANODIC STRIPPING VOLTAMMETRY WITH SUPERIMPOSED A.C. POTENTIAL*
}

\author{
U. Eisner**, C. Yarnitzky, Y. Nemirowsky and M. Ariel \\ Laboratory of Analytical Chemistry, Department of Chemistry, \\ Technion - Israel Institute of Technology, Haifa
}

\author{
ABSTRACT
}

\begin{abstract}
The combination of a.c. polarography with linear scan anodic stripping voltammetry has been investigated, employing a self-constructed, phase discriminating a.c. attachment. The resolution and sensitivity of the method was compared with those obtainable, under similar experimental conditions, by plain anodic stripping voltammetry. Changes in the concentration of the supporting electrolyte and the presence of dissolved oxygen frequently affect the sensitivity and must be carefully controlled. The practical application of the method is illustrated by applying it to the determination of zinc in solutions and in a standard silicate sample.
\end{abstract}

The application of anodic stripping voltammetry to the solution of analytical problems concerning the determination of low concentrations is well on the way to become an established technique $[1,2]$; the hanging mercury drop electrode is most frequently employed [3], although some recent applications involve other electrodes and especially graphite [4]. The method allows the determination of metals deposited as amalgams, as a thin metallic film (on solid electrodes) or as an insoluble film [5].

A.C. polarography, as compared to classical linear voltage scan polarography, offers improved sensitivity and resolution; the quantitative evaluation of successive peaks is convenient. The method is also useful for the study of the kinetics of electrochemical reactions.

In this work, the combination of A.C. polarography with Anodic Stripping Voltammetry has been investigated. It was compared to plain (linear voltage scan) anodic stripping, critical attention having been paid to the points of difference of the two methods.

The combination of anodic stripping and a square wave pulse has been attempted [6]; the equation describing the current-potential relationship applicable to the combination of $\mathrm{A} . \mathrm{C}$. and anodic stripping has been elaborated [7].

* This work was performed under the partial sponsorship of the U.S. National Bureau of Standards. Reproduction of this article, with the customary credit to the source, is permitted.

** Present address: Dept. of Chemistry, The University of Michigan - Ann - Arbor, Mich.

RECEIVED: August 21, 1966 


\section{Apparatus}

A. C. polarographs have been known for a considerable time and a number are available commercially. These instruments may be classified as follows: a. instruments recording the total a. c. current; b. instruments discriminating between the capacity current and the faradaic current, by exploiting the phase difference between them. The advantages of the second class are well known [8].

The availability of operational amplifiers greatly simplifies the construction of a.c. polarographs; these may be readily adapted to required specifications and are often preferable to available commercial apparatus. The instrument employed in the present work was constructed in our laboratory, from inexpensive transistorised amplifiers, as an attachment to a linear scan polarograph. Compared to the apparatus proposed by Smith [9] it has one limitation: a small $\left(5 \times 10^{-8} \mathrm{~A}\right)$ current passes through the reference electrode (vs $10^{-10} \mathrm{~A}$ in Smith's apparatus); while this current is too small to polarize the usual electrodes employed in polarography, it obviously precludes the use of commercial electrodes of the kind often employed in potentiometry.

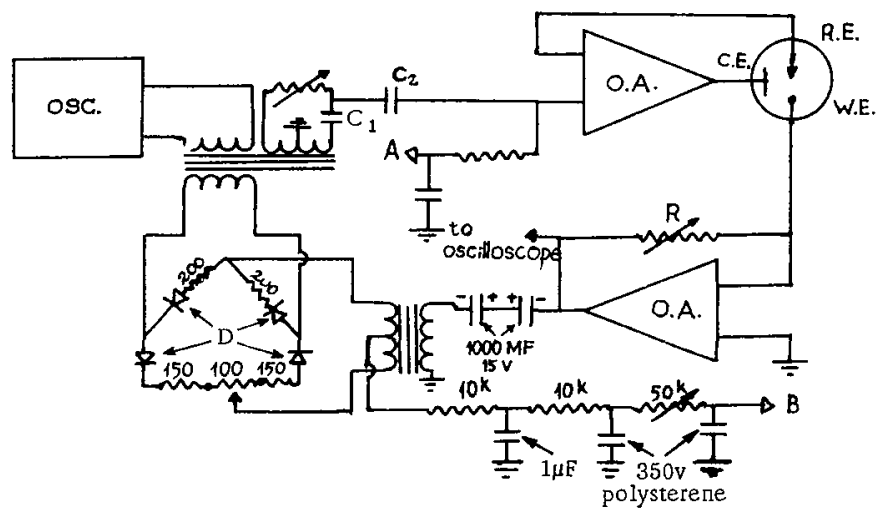

Figure 1

Outline of A. C, attachment

$$
\begin{gathered}
\text { A - to polarograph voltage supply } \\
\text { terminal (Leeds and } \\
\text { Northrop type E Electro- } \\
\text { chemograph) } \\
\text { B - to polarograph current } \\
\text { measuring terminal } \\
\mathrm{C}_{1} \text { - phase shift capacitor } \\
\mathrm{C}_{2} \text { - attenuation capacitor }
\end{gathered}
$$

$$
\begin{aligned}
& \text { C. E.- Counter Electrode } \\
& \text { D - Silicon diode } 1001 \\
& \text { O. A. - Operational Amplifier type ADO- } \\
& \quad \text { 3, Fairchild } \\
& \text { OSC. - Audio oscillator } \\
& \text { R - Sensitivity determining resistor } \\
& \text { R. E. - Reference Electrode } \\
& \text { W.E. - Working Electrode }
\end{aligned}
$$

An outline of the A.C. attachment is given in Figure 1. An outlet to an oscilloscope allows the total current passing through the cell to be monitored; the oscilloscope image should have the shape of a sinusoidal current superimposed on a d. c. current. However, owing to distortions 
of the sinusoidal voltage, the current, too, is distorted (Figure 2). Whenever circuit resistance rises (owing to a malfunction of the electrode, etc.) these distortions disappear, indicating at once the presence of a fault in the system.

Regular and A.C. polarograms, obtained with a $10^{-5} \mathrm{M}$ zinc ion solution, are compared in Figure 3 .

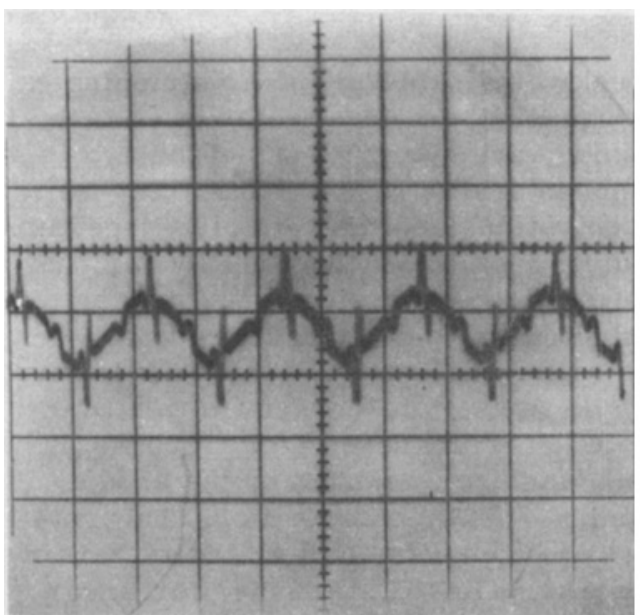

a

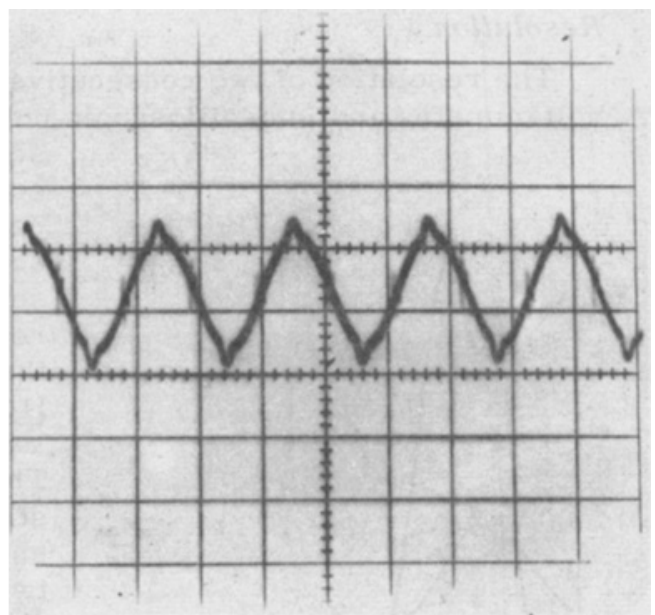

$\mathrm{b}$

Figure 2

a. Distortions in cell current; b. Smoothed out cell current, indicating faulty system.
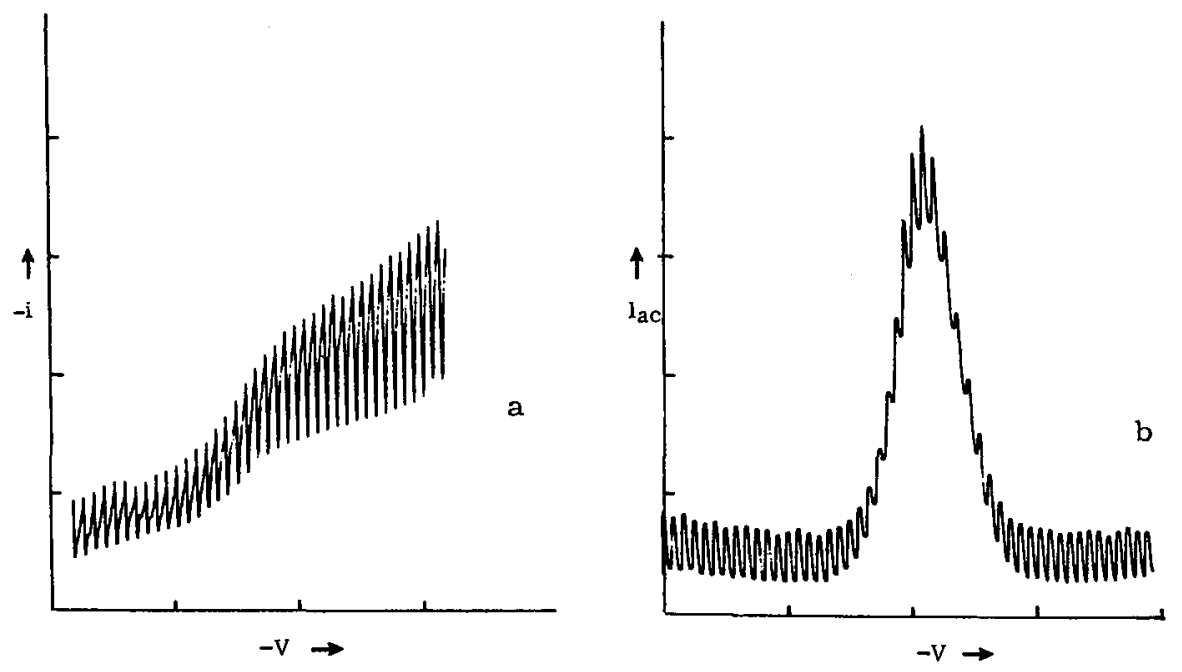

Figure 3

Comparison of (a) regular and (b) A. C. polarograms obtained with a $10^{-5} \mathrm{M} \mathrm{Z \textrm {n } ^ { + 2 }}, 0.1 \mathrm{M} \mathrm{KGl}$ solution. 


\section{Experimental and Results}

The experiments discussed below are described in detail under each figure in which the results are displayed. In principle, the methodology employed in the pre-electrolysis, rest period and scanning steps, is an exact replica of that accepted in regular anodic stripping voltammetry [2]; the only difference is the superposition of an a.c. potential on the linear voltage scan.

\section{Resolution}

The resolution of two consecutive peaks obtainable in anodic stripping voltammetry and in oscilloscopic polarography, for equal rates of voltage

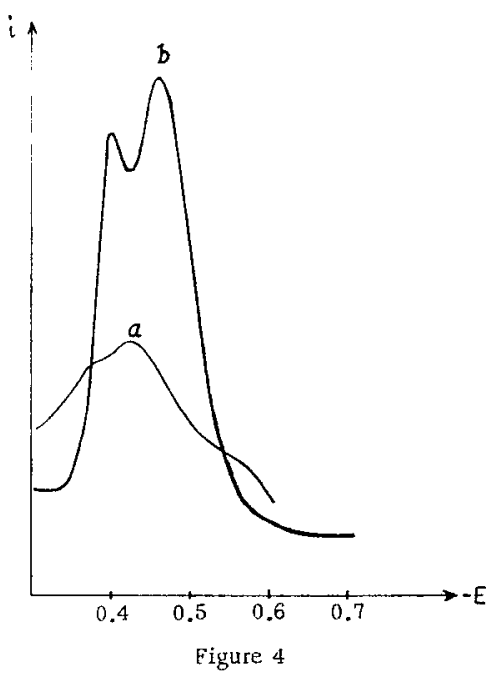

Comparison of resolution of consecutive peaks in the methods of plain anodic stripping and the A.C. - anodic stripping combination $2 \times 10^{-7} \mathrm{M} \mathrm{Pb}^{+2}$ and $2 \times 10^{-7} \mathrm{M} \mathrm{Tl}^{+1}$ in $0.1 \mathrm{M}$ $\mathrm{KCl}$ solution; $\Delta \mathrm{E}_{\frac{1}{2}}=60 \mathrm{mv}$; electrolys is potential: $-1.0 \vee$ vs SCE; stripping scan range $:-0.7 v$ to $-0.35 v$ vs SCE.

a. anodic stripping: electrolysis period: 10 $\mathrm{min}$; tate of linear voltage scan: $3 \mathrm{mv} / \mathrm{sec}$; sensitivity $1 \mu \mathrm{A} /$ full scale

b. A. C. - anodic stripping combination: electrolysis period: 1 min; alternating potcntial: $10 \mathrm{mv}$ p-p: frequency: $80 \mathrm{cps}$; rate of linear voltage scan: $3 \mathrm{mv} / \mathrm{sec}$. scanning, are similar. When the two components are present in similar concentrations and the rate of voltage scanning does not exceed $100 \mathrm{mv}$ per second, two consecutive peaks may be resolved, provided the difference between their half-wave potentials, $\Delta \mathrm{E}_{\frac{1}{2}} \geqslant 150 \mathrm{mv}$ [10]. In A.C. Polarography with a DME, resolution is improved $\left(\Delta \mathrm{E}_{\frac{1}{2}} \geqslant 50 \mathrm{mv}[11]\right.$.) This advantage is shared by the anodic stripping - A.C. combination. Figure 4 shows the comparison of the resolution of two peaks, with $\Delta \mathrm{E}_{\frac{1}{2}}=60 \mathrm{mv}$, for linear scan and a. c. anodic stripping.

For a species undergoing a two electron reaction, $10 \%$ of the peak height is reached when the potential difference: $\mathrm{E}-\mathrm{E}_{\mathrm{p}}$ (between the electrode potential and the peak potential) is $47 \mathrm{mv}$ (at $27^{\circ} \mathrm{C}$ ); at $5 \%$ peak height, $\mathrm{E}-\mathrm{E}_{\mathrm{p}}$ is $56 \mathrm{mv}$, and at $1 \%-78 \mathrm{mv}$. These figures allow the calculation of the error resulting from the overlapping of two consecutive peaks: for two peaks of equal height, and whose peak potentials differ by $75 \mathrm{mv}$, this error does not exceed $1 \%$ (no quantitative evaluation is possible, in the parallel case, when plain anodic stripping is employed, owing to almost complete overlapping of the peaks).

\section{Sensitivity}

The sensitivity of A.C. Polarography exceeds that of the classical D.C. method; this has been illustrated in Figure 3 .

Increased sensitivity is limited to ions undergoing reversible electrochemical reactions; irreversible reactions are accompanied by a 
significant decrease in sensitivity (parallelling the decrease in the rate constant of the electrochemical reaction). This sensitivity may be exploited in the case of low concentrations of a reversibly reacting species in the presence of considerable amounts of an irreversible reactant. In favorable cases no interference due to the presence of the latter is evident.

The absence of oxygen interference has been cited by numerous authors with regard to a. c. determinations of lead, cadmium, etc.

For reversible reactants, a comparison of plain anodic stripping with the a.c. - anodic stripping combination (given the same experimental conditions of stirring, pre-electrolysis, etc.) shows that the latter allows sensitivity to be increased by one order of magnitude [7]. This increase is retained, though to a lesser degree for slightly irreversible reactions.
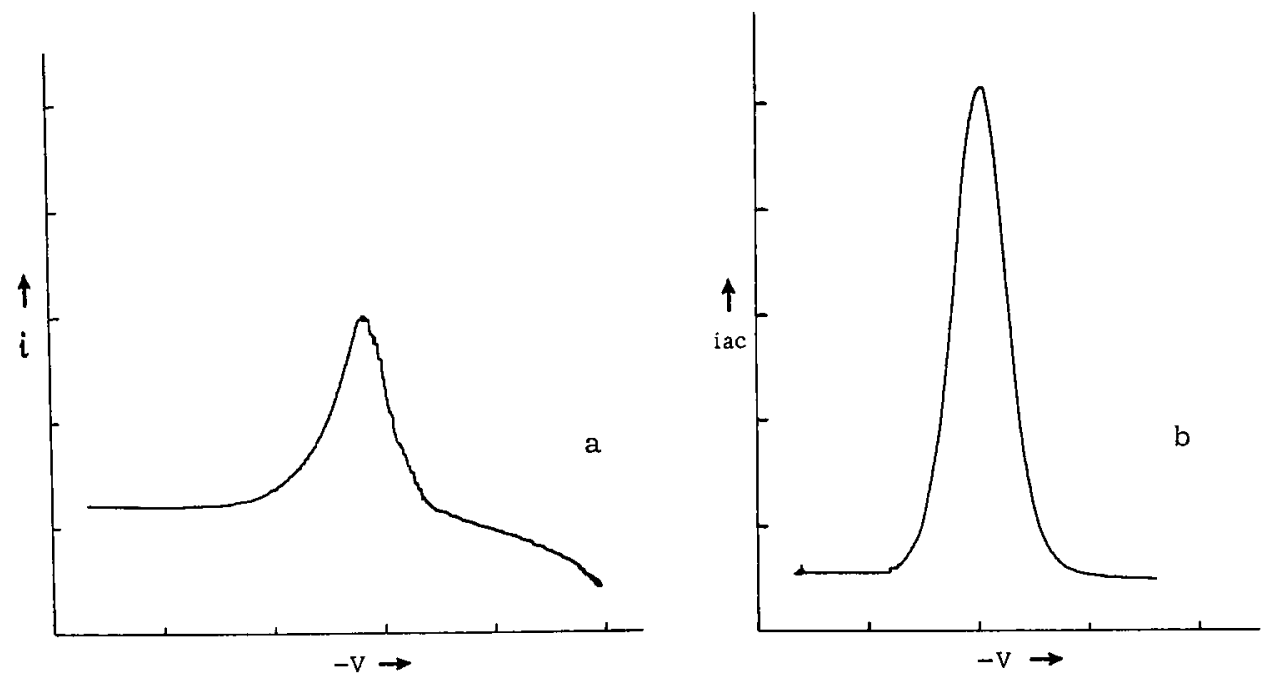

Figure 5

Comparison between: a. plain anodic stripping voltammetry anc b. A. C. - anodic stripping combination in $5 \times 10^{-7} \mathrm{M} \mathrm{Cd}^{+2}$ solution, $0.1 \mathrm{M} \mathrm{KCl}$; a. electrolysis period: $3 \mathrm{~min}$; recorder sensitivity: $0.1 \mu \mathrm{A} / \mathrm{div}$; b. electrolysis period: $1 \mathrm{~min}$; recorder sensitivity: $0.3 \mu \mathrm{A} / \mathrm{div}$. Alternating potential: $10 \mathrm{mv} \mathrm{p}-\mathrm{p}$; frequency: $80 \mathrm{cps}$; rate of linear voltage scan: $3 \mathrm{mv} / \mathrm{sec}$.

A $5 \times 10^{-7} \mathrm{M}$ zinc ion solution in $0.1 \mathrm{M}$ HOAc buffer ( $\mathrm{pH} 4.5$ ) was used to illustrate the method. The comparative results are shown in Figure 5.

\section{Quantitative determinations}

The a. c. current is proportional to the concentration of metal in the amalgam, reaching its peak value when the electrode potential reaches the value of the half-wave potential of the metal in the given supporting electrolyte (for reversible reactions) [7]. The concentration of the metal in the amalgam is proportional to the concentration of the metal ion in 


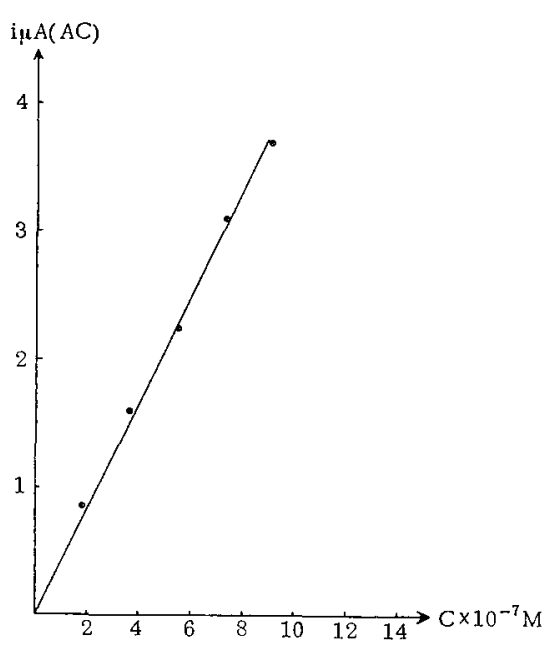

Figure 6

\section{Calibration graph for $\mathrm{Zn}^{+2}$}

Suporting electrolyte: $0.1 \mathrm{M} \mathrm{KCl,} \mathrm{(+} \mathrm{HCl}$, $\mathrm{pH} 3$ ); rate of linear voltage scan: $3 \mathrm{mv} / \mathrm{sec}$; frequency: $80 \mathrm{cps}$; alternating potential: $10 \mathrm{mv}$ p-p.

stripping and square wave polarography were used [6].

In this work the cadmium peak was found to be unaffected by variations in $\mathrm{KCl}$ concentration of the supporting electrolyte, while the height of the zinc peak decreased appreciably with increased $\mathrm{KCl}$ content (up to about $0.1 \mathrm{M} \mathrm{KCl}$ ). The shape of the peak height vs $\mathrm{KCl}$ concentration curves obtained were similar to those reported by Sturm and Ressel [13]. Similar results were obtained when $\mathrm{KNO}_{3}$ was substituted for $\mathrm{KCl}$ (Figure 7).

As a consequence of the above, the amount of reagents employed in sample preparation should be kept as low as possible, so that the final supporting electrolyte is sufficiently dilute and sensitivity is not unduly impaired (for the determination of a metal ion present at the $10^{-6} \mathrm{M}$ concentration level, the concentration of the supporting electrolyte need not exceed $10^{-3} \mathrm{M}$; a three electrode cell, exploiting potential control, removes difficulties resulting from solution resistance).

Polarographic experiments with a $10^{-4} \mathrm{M}$ zinc ion solution, at varying concentrations of $\mathrm{KCl}(0.03 \mathrm{M}$ to $0.4 \mathrm{M} \mathrm{KCl})$ confirmed that the reversibility of the electrochemical zinc reaction decreases with increasing $\mathrm{KCl}$ concentration. 


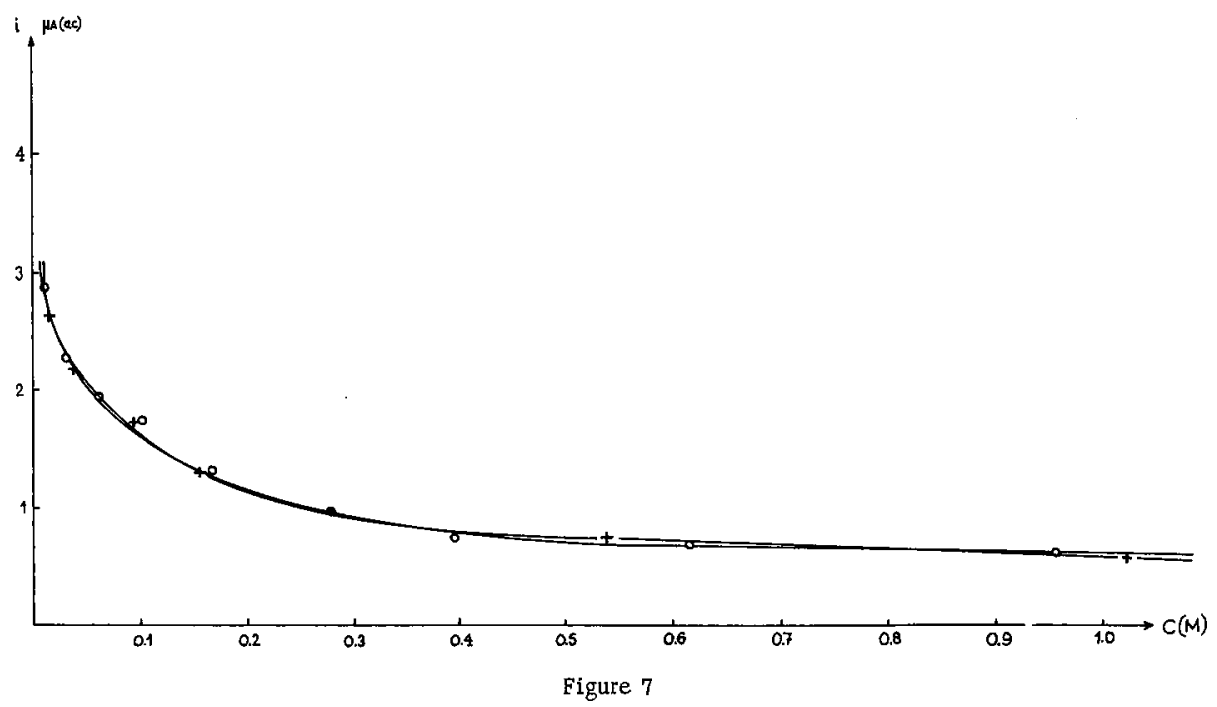

Height of zinc peak as a function of the supporting electrolyte concentration

Concentration of zinc ion solution: $6.5 \times 10^{-7} \mathrm{M}$ i pH 4.5; electrolysis period: 1 min; frequency: $80 \mathrm{cps}$; alternating potential: $10 \mathrm{mv} \mathrm{p}-\mathrm{p}$; rate of linear voltage scan: $800 \mathrm{mv} / \mathrm{min}$. $+-\mathrm{KNO}_{3}$ solution; $\mathrm{O}-\mathrm{KCl}$ solution.

\section{Oxygen}

Oxygen is reduced irreversibly at the mercury electrode and has, therefore, been considered harmless in the course of the a. c. polarography of reversibly reduced species [11].

In this work the zinc oxidation peak was recorded at $-0.96 \mathrm{v}$ vs SCE (in $0.1 \mathrm{M} \mathrm{KCl}$ ); however, an additional peak was frequently observed at $-1.10 \mathrm{v}$, disappearing whenever oxygen had been scrupulously removed from the sample solution.

The splitting of the zinc peak has been reported for $10^{-3} \mathrm{M}$ zinc ion solution [14]. It seems that during pre-electrolysis, at $-1.2 \mathrm{v}$ vs $S C E$, oxygen present in the sample solution is reduced according to: $\mathrm{O}_{2} \rightarrow 2 \mathrm{OH}^{-}$; as a result, during the subsequent rest period (without stirring), the $\mathrm{pH}$ of the solution in the vicinity of the electrode rises; if the sample solution has a $\mathrm{pH}$ in the $5-6$ range, the vicinity of the electrode becomes sufficiently basic for zinc hydroxide to form, giving rise to the additional peak. At the same time, the height of the normal zinc oxidation peak is decreased. This effect is also observed in $\mathrm{KCl}-\mathrm{HCl}$ solutions of $\mathrm{pH} 4.5$.

The decreased height of the normal zinc peak, in the presence of the additional (zinc hydroxide) peak, may be ascribed to the impeding influence of film formation on the electrode surface.

\section{Applications of the method}

The determination of zinc in NBS sample No. 91 (Opal Glass containing $0.08 \% \mathrm{ZnO}$ ) was chosen to illustrate the practical potentialities of the method. The sample was dissolved by acid attack, diluted and its $\mathrm{pH}$ 
adjusted to 3; an aliquot was introduced into the electrolysis cell containing $0.05 \mathrm{M} \mathrm{KCl}$ (adjusted to $\mathrm{pH} \mathrm{3}$ ) and analysed. The results obtained agreed with those obtained by regular anodic stripping [15]. For samples with low zinc content, a considerable saving of electrolysis time is obtained.

The presence of traces of platinum (frequently introduced from the platinum utensils, during sample attack) diminishes the height of the zinc peak in anodic stripping voltammetry [15]; this effect has been observed in this work. The zinc peak decreases linearly with increased platinum concentration, finally disappearing entirely (Figure 8). In contrast to anodic stripping voltammetry the base line is unaffected by the catalytic hydrogen reduction [15].

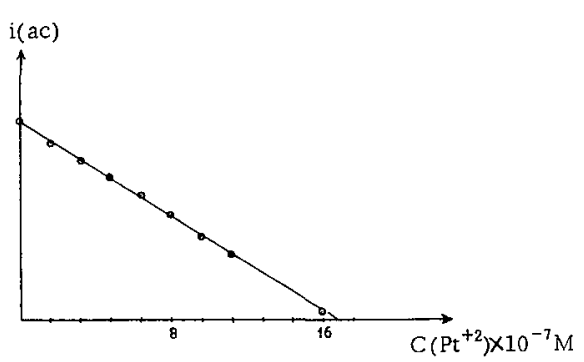

Figure 8

Height of zinc peak as function of the concentration of platinum ions.

$6.9 \times 10^{-7} \mathrm{~m} \mathrm{Zn}^{+2}$ in $0.1 \mathrm{M} \mathrm{KCl}(+\mathrm{HCl}, \mathrm{pH}=2.5$ ) solution. Frequency: $180 \mathrm{cps}$; alternating potential: $10 \mathrm{mv} \mathrm{p-p.}$

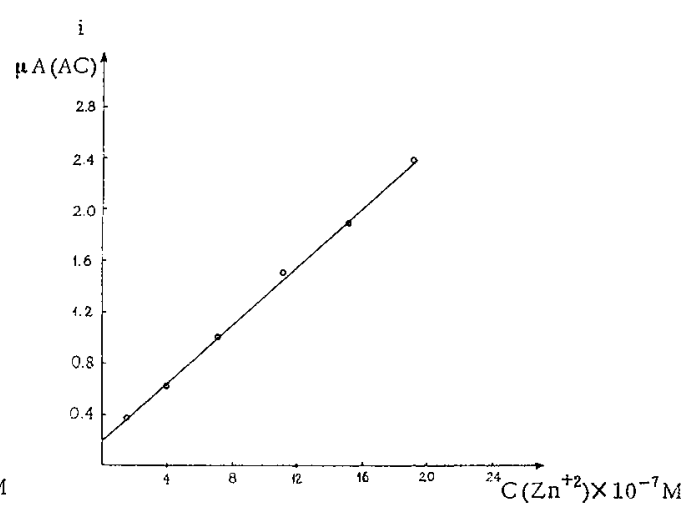

Figure 9

Calibration graph for $\mathrm{Zn}^{+2}$ in the presence of $1.6 \times 10^{-4} \mathrm{M} \mathrm{Fe}^{+3}$.

Supporting electrolyte: $0.1 \mathrm{M} \mathrm{KCl}$ solution ( $+\mathrm{HCl}$, $\mathrm{pH} 2.8$ ); rate of linear voltage scan: $3 \mathrm{mv} / \mathrm{sec}$; alternating potential: $10 \mathrm{mv} \mathrm{p}-\mathrm{p}_{\mathbf{i}}$ frequency: $80 \mathrm{cps}$.

The simultaneous reduction of iron was shown to be a source of potential interference in the determination of zinc in silicates by anodic stripping voltammetry [15]; no such interference is observed in the a. c. - anodic stripping combination, since the $\mathrm{Fe}^{+3} \rightarrow \mathrm{Fe}^{+2}$ reduction proceeds irreversibly in the medium employed ( $\mathrm{KCl}$ solution); zinc may, therefore, be determined in the presence of considerable iron (Figure 9).

The choice of pre-electrolysis potential becomes critical in this case; at the potential chosen ( $-1.2 \mathrm{v}$ vs $\mathrm{SCE})$, the reduction of ferrous iron to metal does not occur; whenever more negative (up to $-1.5 \mathrm{v}$ ) potentials were used, the height of the zinc peak decreased. A similar effect has been reported [16] and attributed to the formation of compounds of the type $\mathrm{Fe}_{\mathrm{x}} \mathrm{Zn}_{\mathrm{y}}$. 


\section{REFERENCES}

1. I. SHAIN, in: Treatise on Analytical Chemistry, I. M. Kolthoff and P.J. Elving, eds, , Part 1, Vol. 4, chap. 50, Interscience N. Y., (1963)

2. M. ARIEL and U. EISNER, J. Electroana1. Chem., 5, 362 (1963)

3. W. KEMULA, in: Advances in Analytical Chemistry and Instrumentation, C. N. Reilley, ed., Vo1. 2, p. 123, Interscience N. Y., (1963)

4. S.P. PERONE and W.I. KRETLOW, Ana 1. Chem. 37, 968 (1965)

5. KH. Z. BRAININA et al, , Zh. Anal, Khim., 18, 1167 (1963)

6. F. V. STURM and M. RESSEL, Z. A n a l. Chem., 186, 63 (1962)

7. W. L. UNDERKOFLER and I. SHAIN, Ana 1. Ghem. , 37, 218 (1965)

8. G. W. HAYES and H. H. BAUER, J. Electroanal. Chem., 3, 336 (1962)

9. D. E. SMITH, Anal. Chem., 35, 1811 (1963)

10. U. EISNER, D. Sc. Thesis, Technion - Israel Institute of Technology (1965)

11. H. H. BAUER, J. Ele ctroan a l. Chem. 1, 373 (1959-60)

12. I. SHAIN and I. LEWINSON, Ana 1. Chem., 33, 187 (1961)

13. F. v. STURM and M. RESSEL, M i crochem. J. , 5, 53 (1961)

14. T. TAKAHASHI and H. SHIRAI, J. Electroana1. Chem., 1, 331 (1959-60).

15. G. KOSTER, U. EISNER and M. ARIEL, Z. Ana l. Chem. (in press)

16. R. KALVODA, Coll. Czech. Chem. Commun., 22, 1390 (1957) 